\title{
Plagiarism Bros. CTRL-C and CTRL-V are Under Surveillance
}

Plagiarism, taking written material (i.e. sentences, words, ideas, etc.) of other people without adequate citation, is one of the most common types of misconduct in scientific publication. It may have a spectrum of consequences from simply copying a sentence to data theft. Elizabeth Wager of the Committee on Publication Ethics (COPE) states that "the theft of data may constitute not only plagiarism but also data fabrication since the work was not done by the copier" (1). The mildest part of this spectrum, i.e. academic laziness, means, at best, wasting of resources and violation of copyrights. Wager also draws attention to the difference between a standard phrase and original use. Standard phrases such as "central sleep apnea patients with hypertension" or "statistically significance level was adjusted to $p<0.05$ " or "This study was conducted in accordance with the ethical regulations of animal experimentation" should not be accepted as plagiarism, although all these examples contain more than 6 words and may be seen verbatim in many texts. We, as the editors, must distinguish between standard phrases and original usage when considering plagiarism. Wager (1) also proposes a word count limit to define major plagiarism (copying of $>100$ words without citation) and minor plagiarism (copying of $<100$ words). Another useful editorial paper written by Shafer (2) describes 5 different types of plagiarism from the most serious to the least deceitful: "intellectual theft, intellectual sloth, plagiarism for scientific English, technical plagiarism, and self-plagiarism". In that paper, definition of technical plagiarism stresses that referencing to the original source does not always rescue an author from being caught as a delinquent. Even when you use your own words from a previous paper in a new manuscript, you should limit this into $30 \%$ rule in order to stay away from self-plagiarism (3). Another discussion comes from Habibzadeh and Shashok (3). They suggest that taking the scientific content rather than wording should be discredited. Considering the number of published articles in a year, in the near future it will not be possible to express any idea without inventing new words in order to prevent text similarity. The debate seems to go on and editors will be the most critical part of it.

I explicitly express that in my opinion, Methods section of a manuscript may contain text similarities. In how many different ways can we define measuring blood pressure or recording electroencephalogram? Many researchers use the same experimental set up or an animal model for consecutive studies. In how many different ways can we define total sleep deprivation or cerebral ischemia-reperfusion models in rats?
Maybe, medical associations and societies should create uniform definitions for standard procedures that can be used by all authors in the Methods sections of their manuscripts. Anyway, until a better solution is available, we have to courage authors to write their own sentences rather than simply copy $(C T R L+C)$ and paste $(C T R L+V)$ from other sources.

As in the many other scientific journals, we have now got the opportunity to use a software program for identifying texts taken verbatim from previously published articles. Balkan Medical Journal announces that every submitted manuscript will be routinely screened for plagiarism by using the iThenticate tool. In case of significant overlap with previously published material, we will follow COPE guidelines and take appropriate action $(4,5)$. These may include warning authors to amend the text, using quotation marks for giving due credit, or rejecting the submitted manuscript besides informing the head of author's institution. Taking appropriate precautions to prevent plagiarism should be one of the overarching missions of not only editors but also authors, and be acquired as a habit. By these warnings, we want to urge authors to perform their own screening against plagiarism before submission process. I have started from myself and screened text similarities of this editorial paper and verified the originality of its content. I believe each author of Balkan Medical Journal is going to do his/her best to avoid unethical appropriation of material which belong to others. Don't be an associate of plagiarism bros., CTRL-C and CTRL-V.

\section{Levent Öztürk, MD \\ Editor-in-Chief, Balkan Medical Journal, Department of Physiology, Trakya University Faculty of Medicine, Edirne, Turkey}

\section{References}

1. Wager E. How should editors respond to plagiarism? COPE discussion paper. COPE 2011 http://www.publicationethics.org/ files/ COPE_plagiarism_disc\%20doc_26\%20Apr\% 2011. pdf (Accessed Oct 24, 2011).

2. Shafer SL. You will be caught. Anesthesia \& Analgesia 2011;112:491-3. [CrossRef]

3. Habibzadeh F, Shashok K. Plagiarism in scientific writing: words or ideas? Croat Med J 2011;52:576-7. [CrossRef]

4. Committee on Publication Ethics. What to do if you suspect plagiarism. 2008. http://publicationethics.org/fi les/u2/02A_Plagiarism_Submitted.pdf (Accessed Oct 24, 2011).

5. Committee on Publication Ethics. What to do if you suspect plagiarism. 2008. http://publicationethics.org/fi les/u2/02B_Plagiarism_Published.pdf (Accessed Oct 24, 2011). 